and the EoLC workforce levels. It is collaboration across Beds and Herts End of Life Network: 3 PCTs, 2 Cancer Networks, 8 independent hospices, 5 acute trusts, 3 community trusts. The coordinated approach is to ensure quality and standardisation. Guidance alone is not able to embed the advance care planning process in practice. The model ${ }^{1}$ provides templates for facilitators to deliver the variety of education required for different audiences which include patients, carers and the public. The model ${ }^{1}$ uses national documentation and resources for professionals and patients.

Steps in the model $^{1}$ are: identifying the workforce, identifying different levels of education, delivering education, measuring confidence levels, evaluation, and measurement of impact and consideration of sustainability.

The model ${ }^{1}$ includes, raising public and professional awareness of what ACP is and who it should matter to, delivering the skills to instigate it and the skills for teaching ACP. A blended learning approach includes face to face learning, e-learning using the National e-learning modules and the East of England EoLC care home education project

The model ${ }^{1}$ is part of implementation guidance, including: communication, information transfer, documentation, process and a competency based learning framework, so that learning is part of a wider learning experience in End of Life Care.

Passion, persistence and pennies: examples of area wide strategic spread

\title{
65 BEDFORDSHIRE AND HERTFORDSHIRE ADVANCE CARE PLANNING EDUCATIONAL MODEL
}

10.1136/bmjspcare-2011-000053.65

S Russell', C Fowler ${ }^{1}$ Hospice of St Francis; ${ }^{2}$ Mount Vernon Cancer Network Education Lead

The model ${ }^{1}$ responds to the challenges of implementing guidance on advance care planning using levels of education need, 